\title{
The Sliding and Overturning Analysis of Spent Fuel Storage Rack Based on Dynamic Analysis Model
}

\author{
Yu Liu, ${ }^{1,2}$ Daogang Lu, ${ }^{1,2}$ Yuanpeng Wang, ${ }^{1,2}$ and Hongda Liu ${ }^{1,2}$ \\ ${ }^{1}$ School of Nuclear Science and Engineering, North China Electric Power University, Beijing 102206, China \\ ${ }^{2}$ Beijing Key Laboratory of Passive Safety Technology for Nuclear Energy, North China Electric Power University, \\ Beijing 102206, China \\ Correspondence should be addressed to Yu Liu; appleplanter@gmail.com
}

Received 20 January 2016; Revised 2 June 2016; Accepted 12 June 2016

Academic Editor: Borut Mavko

Copyright (C) 2016 Yu Liu et al. This is an open access article distributed under the Creative Commons Attribution License, which permits unrestricted use, distribution, and reproduction in any medium, provided the original work is properly cited.

\begin{abstract}
Spent fuel rack is the key equipment for the storage of spent fuel after refueling. In order to investigate the performance of the spent fuel rack under the earthquake, the phenomena including sliding, collision, and overturning of the spent fuel rack were studied. An FEM model of spent fuel rack is built to simulate the transient response under seismic loading regarding fluid-structure interaction by ANSYS. Based on D'Alambert's principle, the equilibriums of force and momentum were established to obtain the critical sliding and overturning accelerations. Then 5 characteristic transient loadings which were designed based on the critical sliding and overturning accelerations were applied to the rack FEM model. Finally, the transient displacement and impact force response of rack with different gap sizes and the supporting leg friction coefficients were analyzed. The result proves the FEM model is applicable for seismic response of spent fuel rack. This paper can guide the design of the future's fluid-structure interaction experiment for spent fuel rack.
\end{abstract}

\section{Introduction}

Free standing spent fuel storage racks are submerged in water contained in a pool. During a postulated strong motion earthquake, the water surrounding the racks and fuel assemblies is accelerated and the so-called fluid-structure hydrodynamic interaction is significantly induced between the water and the fuel assemblies, the racks and the pool walls [1]. Fluid-structure interaction (FSI) problems have attracted a great deal of attention because of their wide range of applicability [2,3]. Axisa and Antunes [4] have classified FSI effect by fluid inertia effects, sloshing effect, fluid elasticity effect, and damping effect. According to the report [5] by NRC, for the evaluation of fluid effect for spent fuel rack, as a basic assumption, the inertial effect of water on the vibrating structures is considered while fluid damping and sloshing effects are generally ignored.

The verification of structural integrity and functionality is performed in two steps [6]. In the first phase, the motional behavior of single racks is simulated by excitation with time histories under consideration of the fluid-structure interaction (FSI), which will be described in the next section. In the second phase, the loads from the first phase are utilized as input data for the structure analysis to substantially get stress analyses. The analytical method for second phase is just a basic quasistatic analysis; moreover, the detailed design data of steel channels, welds, baseplate, and support structure are hard to obtain; therefore, this paper only focuses on the nonlinear analysis for the rack and the structural analysis was not included.

Much attention was paid to the time history analysis of free standing rack. Due to inertia effects and friction, the rack legs may lift off or slide on the pool floor. Such seismic response of the fluid-structure-coupling system may cause the impact between the rack cells and the fuel assemblies that are freely standing inside the rack cells. The complex rack's movement includes not only the impact between rack and pool wall, but also the impact between rack supporting legs and pool floor. The mathematical models usually used to describe such impact and friction phenomena are materially 
TABLE 1: AP1000 spent fuel storage racks data.

\begin{tabular}{lccccc}
\hline Rack & Region & Array size & Storage cell center-to-center pitch (in) & Cell length (in) & Weight (lb) \\
\hline$A 1, A 2, A 3$ & Region 1 & $9 \times 9$ & 0.277 & 5.07 & 13200 \\
$B 1, B 2, B 3$, and $B 4$ & Region 2 & $12 \times 11$ & 0.229 & 5.07 & 11200 \\
$C 1$ & $12 \times 10(-2)$ Region 2 & $12 \times 10(-2)$ & 0.260 & 5.07 & 11400 \\
\hline
\end{tabular}

and geometrically nonlinear, respectively. A 3D nonlinear dynamic time history analysis method is usually needed to solve such nonlinear problems [2]. Analyses of 3D whole pool multiple rack model are much more complicated and computationally costly than a $3 \mathrm{D}$ single rack or a $2 \mathrm{D}$ multiple rack problem [1,7]. Lee et al. [8] performed a transient analysis of 3D rack using ANSYS codes. As a result of the adequacy study, the method of time history analysis is suitable for the seismic analysis of highly nonlinear structure such as spent fuel rack but it is not appropriate to use displacement time history of seismic input. Iwasaki et al. [9] reflected test result to analysis method and developed the dynamic response analysis model of 3D single rack. The results verified the effectiveness of analysis evaluation method of the free standing rack.

According to a report by Westinghouse [10], the friction coefficient proves to be random values ranging from 0.2 to 0.8 . In the report, different values of friction coefficients were utilized to simulate the time history response of rack; therefore, influence of friction coefficient is still required to be studied to guide the design of the rack.

The FSI is characterized by flat structures with large surfaces (area of one rack wall in the order of $10 \mathrm{~m}^{2}$ ) separated by relatively small water gaps (down to the order of $10 \mathrm{~mm}$ ). Motion of neighboring racks can consequently lead to a large fluid pressure on the rack walls. Stabel and Ren [11] compared and evaluated different FSI formulations commonly used, namely, two coaxial cylinders in 3D fluid, and two coaxial squares two coaxial rectangle solids in $2 \mathrm{D}$ and $3 \mathrm{D}$ fluid. It was shown that a proper and consistent formulation which has the potential to account for 3D flow fields and large amplitude displacements of the racks is necessary to avoid errors in the determination of the structural loads.

Although much effort has been paid to the seismic behavior of free standing fuel rack, additional research could provide greater confidence in the analysis methods by reducing the levels of uncertainty. In order to assess the sensitivity of response to variations in model parameters, this paper built a simplified mechanical model of spent fuel rack regarding the fluid-structure interaction. The transient response of rack with different values of fluid gap sizes and the supporting leg friction coefficient were analyzed to estimate the most important factor influencing the rack displacement and impact forces.

\section{The Description of the Rack Model}

2.1. Rack Design Description. As reviewed by Ashar and DeGrassi [5], the honeycomb construction type of fuel rack module as shown in Figure 1 is a common design configuration. Design and fabrication details vary with different

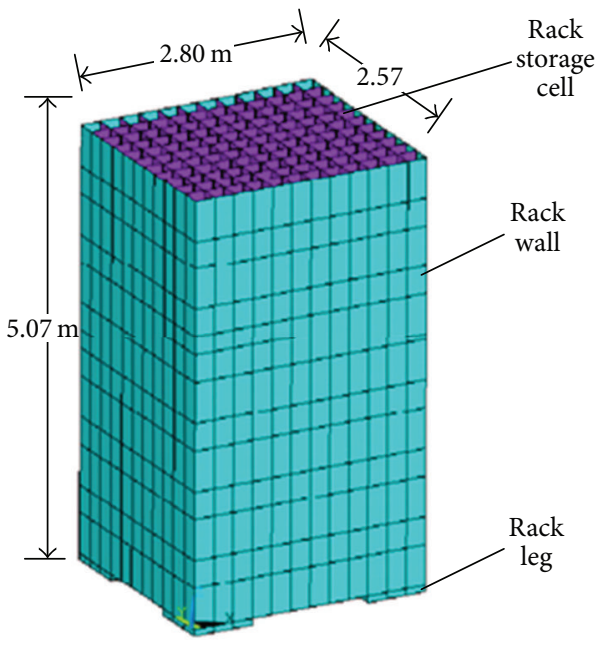

FIGURE 1: A typical fuel rack module.

vendors but the overall design can be described as follows. The module is a welded honeycomb structure which consists of square cross-section stainless steel storage cells. Each cell is designed to accommodate a single spent fuel assembly. The honeycomb structure is welded to a base support assembly which may consist of a base plate with four or more support legs.

A high density spent fuel rack installation may include several modules in a pool. The modules could vary in size and storage capacity. To maximize fuel storage, they are arranged in close proximity to each other and to the pool walls. Gaps of zero to two inches are common. A typical AP 1000 spent fuel pool contains three Region 1 rack modules and five Region 2 rack modules. As reported by Westinghouse [10], the detailed dimension data of spent fuel racks are listed in Table 1.

2.2. Description of Seismic Analysis Methods. According to the design of AP1000, free standing rack is supported by 4 legs as shown in Figure 1. The leg of the rack and the floor of the pool cause friction, and seismic force along with inertia acts as friction force on the rack. When friction increases, rocking behavior which lifts up the legs occurs, and the rack receives fluid force by the fluid around the rack.

The simplified rack analysis model is assembled in one uniform cross-section beam having the same mass of the rack. The parameter of the beam can be obtained by adjusting the equivalent section moment of inertia of the beam to make natural frequency of the simplified model equal to a detailed FEM rack model. The bottom plate is made of relatively thick stainless steel; consequently, it is modeled by a rigid X-shaped frame. 


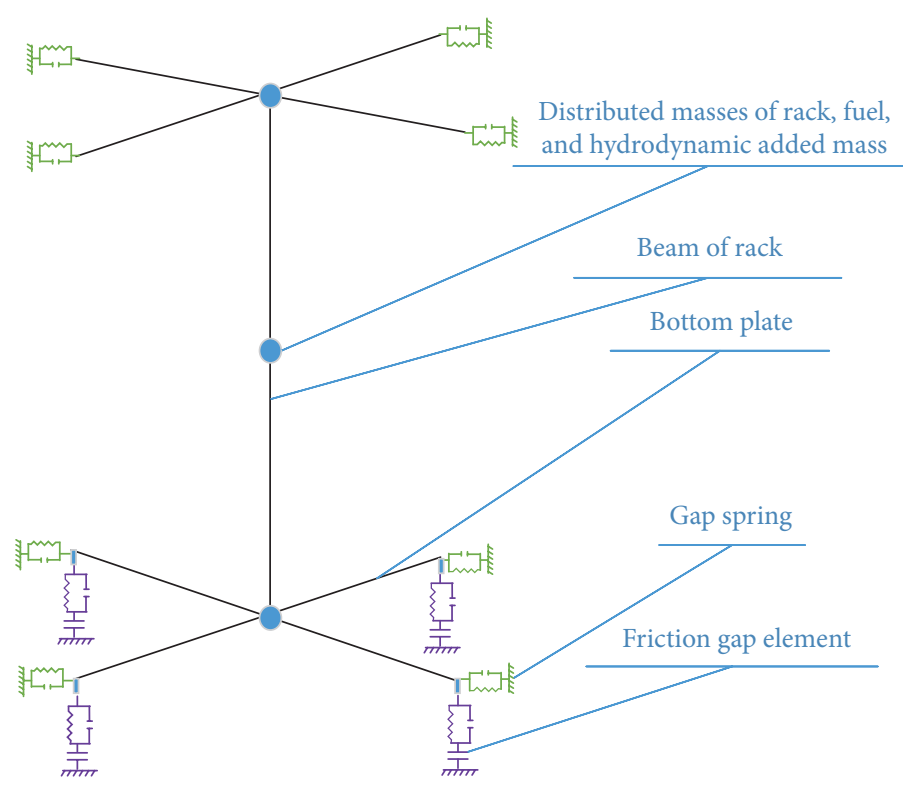

FIgURe 2: Model of free standing fuel rack.

The contact between the leg and the floor is simulated by Coulomb friction model. The static friction coefficient and kinetic friction coefficient were equal. The friction coefficient was set to 0.3 in the water obtained by the vibration test [12].

The impact between the rack and the wall is simulated by gap spring model. This element behaves like a stiff spring until the force reaches a limiting value equal to the specified friction coefficient times the normal force. The spring stiffness can be derived by Hirtz contact theory, which could be automatically calculated by the ANSYS.

When the rack is placed in water, the FSI have to be taken into consideration. According to Ashar and DeGrassi's study [5], the inertial effects of water on the vibrating structures are considered while fluid damping and sloshing effects are generally ignored. The fluid added mass of the rack can be expressed by fluid added mass of a parallelepiped illustrated in Figure 3 [1], which, therefore, denotes

$$
M_{H}=\rho L a_{1}^{2}\left(\frac{a_{1}}{12 g_{1}}+\frac{a_{1}}{12 g_{3}}+\frac{a_{2}}{4 g_{2}}+\frac{a_{2}}{4 g_{4}}\right),
$$

where $M_{H}$ is the hydrodynamic added mass; $\rho$ is the density of the water; $L$ is the height of the rack; $a_{1}$ and $a_{2}$ are the width and length of the rack; $g_{1}, g_{2}, g_{3}$, and $g_{4}$ are the gap sizes around the rack.

The main aim of the paper is to study the sliding, overturning, and impact of the rack. The gaps between the assemblies and the rack are only about $5 \mathrm{~mm}$, relatively smaller than the gaps between the rack and the wall. Consequently, the authors think if the assemblies and the rack are merged together, the sliding distance will be larger and more conservative than that of the coupling one because the distributed mass model ignores the impact and the friction. Consequently, the fuel assemblies are simplified into three distributed masses attaching on the beam of rack illustrated in Figure 2.
TABLE 2: Parameters of rack adopted in the simulation.

\begin{tabular}{lcc}
\hline Rack size & $a_{1}=2 b ; a_{2}$ & $2.57 \mathrm{~m} ; 2.8 \mathrm{~m}$ \\
Rack height & $2 h$ & $5.07 \mathrm{~m}$ \\
Gap size & $g_{1}=g_{3}, g_{2}=g_{4}$ & $0.05 \mathrm{~m} ; 1.00 \mathrm{~m}$ \\
Fluid added mass & $m_{H}$ & $3.30 \times 10^{5} \mathrm{~kg}$ \\
Friction coefficient & $\mu$ & 0.3 \\
Mass of rack & $m_{r}$ & $1.12 \times 10^{4} \mathrm{~kg}$ \\
Mass of total fuel assemblies & $m_{\mathrm{fa}}$ & $1.15 \times 10^{5} \mathrm{~kg}$ \\
\hline
\end{tabular}

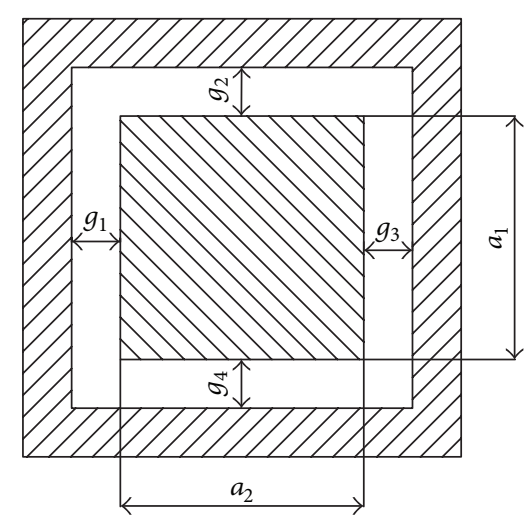

FIgURE 3: Fluid added mass.

2.3. FEM Model. In this paper, the AP1000 rack in Region II is chosen as an example to validate the model. The rack data are listed in Table 2.

Corresponding to the model illustrated in Figure 2, the FEM model by ANSYS codes is illustrated in Figure 4. Contal78 elements are adopted to simulate friction and the impact between leg and the pool. Conbin 40 elements are adopted to simulate the impact between rack and the wall. 


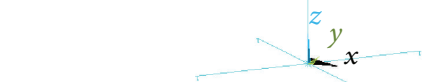

FIGURE 4: FEM model of free standing fuel rack.

The Mass21 elements are used to simulate the distributed mass of the rack, assemblies, and the fluid added mass. The beam 21 element is used to simulate the rack structure.

In the analysis, the spent fuel pool is fixed so it is represented by several nodes which are connected with the conta178 elements and Combin40 elements. The boundary condition for this model is that all the nodes that represent spent pool are fixed. In the time history analysis, transient acceleration loading is input as the inertia; moreover, the gravity is also included.

\section{The Analysis of Sliding and Overturning}

3.1. Critical Sliding and Overturning Acceleration. In order to improve the understanding of the rack motion under earthquake, the rack is assumed to be a rigid body to sketchily provide the critical sliding and overturning accelerations.

First of all, the rack is regarded as a rigid body with planar motion. The rack of mass $m$ is moving on the floor with an acceleration a, caused by the friction. However, it has to be noticed that the friction may be either static or kinetic friction. The distance between two legs is $2 b$. The height of the rack is $2 h$. Here, generally assume that the distance between the barycenter and the floor is $h$.

Under the earthquake, the friction and the fluid forces apply on the rack. Here, the fluid force $\mathbf{F}_{\text {fluid }}=-m_{H} \mathbf{a}$. The inertia force system can be simplified into $\mathrm{F}_{\mathrm{IR}}$ applied on the barycenter, which is in opposite direction of acceleration, according to D'Alambert's principle. Here, the inertia force $\mathrm{F}_{\mathrm{IR}}=-m \mathbf{a}$.

Establish the force and momentum equilibriums using method of dynamic equilibrium. The momentum equilibriums are written as

$$
\begin{aligned}
\sum M_{B} & =0, \\
F_{\mathrm{IR}} h+F_{\text {fluid }} h-G b+F_{N A} 2 b & =0, \\
\sum M_{A} & =0, \\
F_{\mathrm{IR}} h+F_{\text {fluid }} h+G b-F_{N B} 2 b & =0 .
\end{aligned}
$$

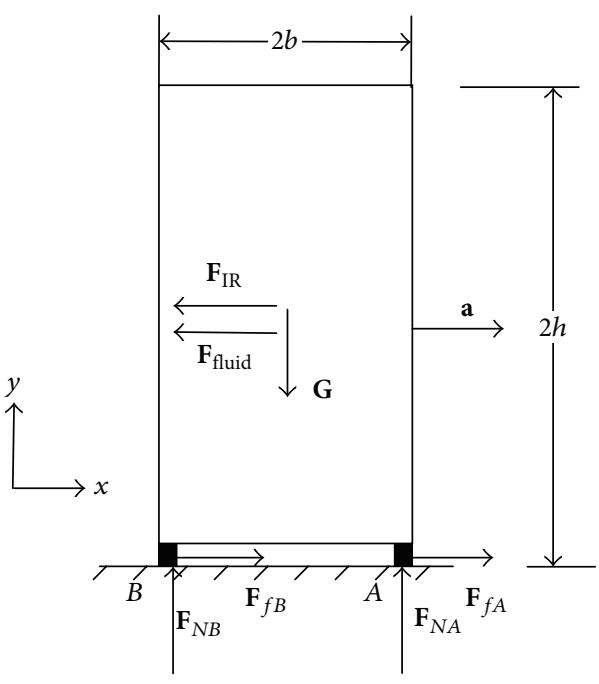

FIGURE 5: The rigid rack model.

We obtain

$$
\begin{aligned}
& F_{N A}=\frac{m g b-\left(m a h+m_{H} a h\right)}{2 b}, \\
& F_{N B}=\frac{m g b+\left(m a h+m_{H} a h\right)}{2 b} .
\end{aligned}
$$

From the above equations, if $a$ is positive, $F_{N A}$ will be smaller than $F_{N B}$. When $F_{N A}$ is 0 , the rack will overturned. Consequently, when the upper equation in (3) equals 0 , we obtained the critical overturning acceleration $a_{\text {co }}$ :

$$
a_{\mathrm{co}}=\frac{m}{m_{H}+m} \frac{b}{h} g=0.081 \mathrm{~g} \text {. }
$$

The above equation shows that the critical overturning acceleration is $m /\left(m_{H}+m\right)$ times $\mathrm{bg} / \mathrm{h}$. This means the fluid added mass can decrease the critical overturning acceleration. The geometry of the rack can also influence the critical overturning acceleration. If the ground acceleration is larger than $a_{\mathrm{co}}$, the rack will overturn.

From Figure 5, the force equilibriums of rack are written as

$$
\begin{aligned}
\sum F_{x} & =0, \\
-F_{\mathrm{IR}} h-F_{\text {fluid }} h+F_{f B}+F_{f A} & =0, \\
\sum F_{y} & =0, \\
F_{N A}+F_{N B}-G & =0 .
\end{aligned}
$$

Assume there is relative sliding between the rack and floor. When Coulomb friction model is introduced, $F_{f A}=$ $\mu F_{N A}$ and $F_{f B}=\mu F_{N B}$. The critical sliding acceleration $a_{\mathrm{cs}}$ is denoted by:

$$
a_{\mathrm{cs}}=\frac{m}{m_{H}+m} \mu g=0.137 \mathrm{~g} .
$$



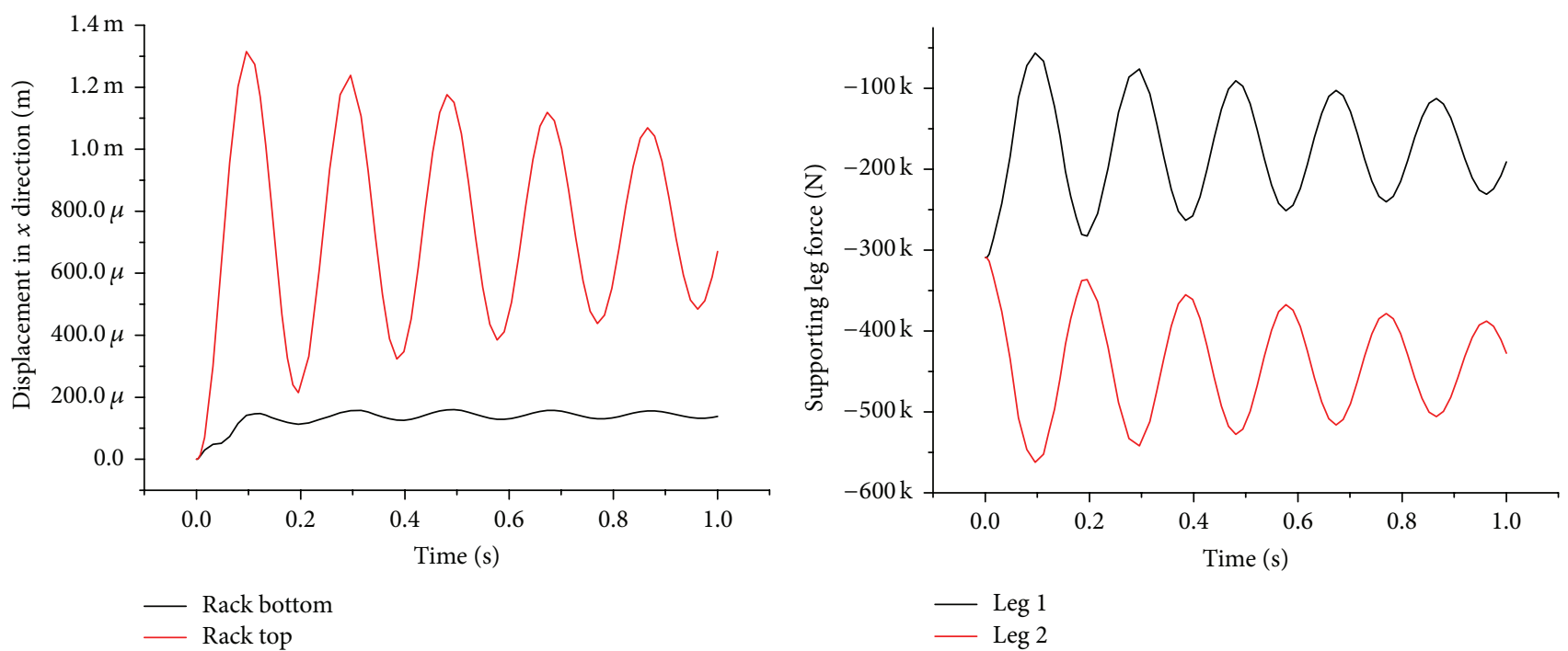

(a)

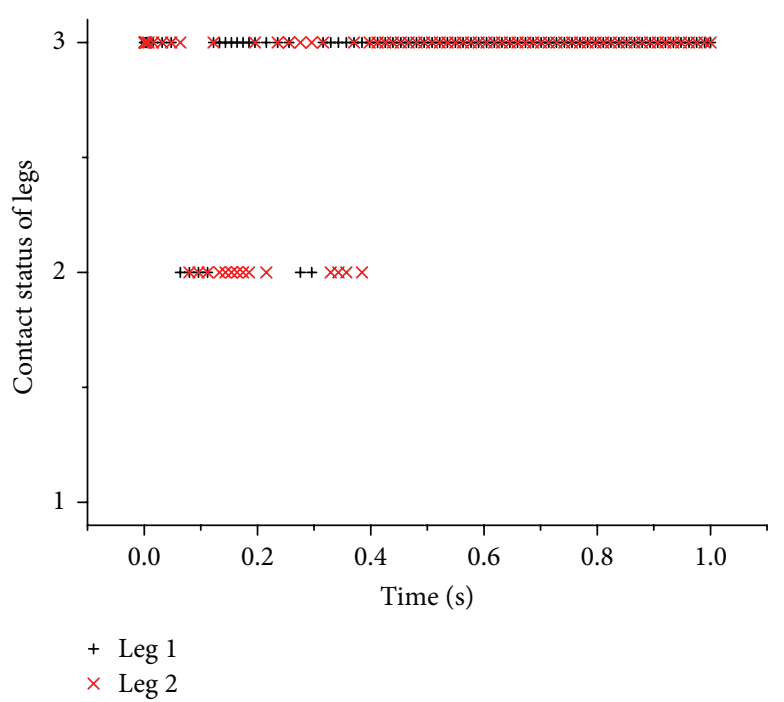

(c)

FIGURE 6: Uniform acceleration amplitude loading: $0.06 \mathrm{~g}$.

The above equation shows that the critical sliding acceleration is $m /\left(m_{H}+m\right)$ times $\mu g$. This means the fluid added mass can decrease the critical sliding acceleration. If the ground acceleration is larger than $a_{\mathrm{cs}}$, the rack will slide on the floor.

In this system, friction is driving force for the rack motion and fluid force is resistance. According to the Coulomb model, if there is relative sliding, the maximum friction is the sliding friction. Consequently, this means the acceleration of rack can never surpass the critical sliding acceleration. If critical overturning acceleration is larger than critical sliding, the rack will not overturn.

3.2. Transient Test. The previous analysis assumes that the rack is a rigid body and the dose is not taken into consideration of the impact. The natural frequency of the loaded rack is above $10 \mathrm{~Hz}$; the rack is not so flexible. This simplification has limited influence on the sliding and overturning effect of the rack. Consequently, the critical sliding and overturning accelerations can be used to test the FEM model discussed in Section 2.

Knowing the critical sliding and overturning acceleration, as listed in Table 3, 5 characteristic loadings in $X$ direction are adopted to test the response of the rack. Loading \#1 is smaller than critical sliding acceleration. Loading \#2 is between the critical sliding acceleration and critical overturning acceleration. Loading \#3 is larger than critical overturning acceleration. Loading \#4 is a sine wave with an acceleration amplitude of $0.4 \mathrm{~g}$. Loading \#5 is a seismic loading with peak ground acceleration $0.4 \mathrm{~g}$.

Figures 6-10 are the time history results of 5 characteristic loading tests. Figure series (a) are time displacement history at the top and bottom of the rack. Figure series (b) are the supporting leg forces in $Z$ direction. Figure series (c) are the 


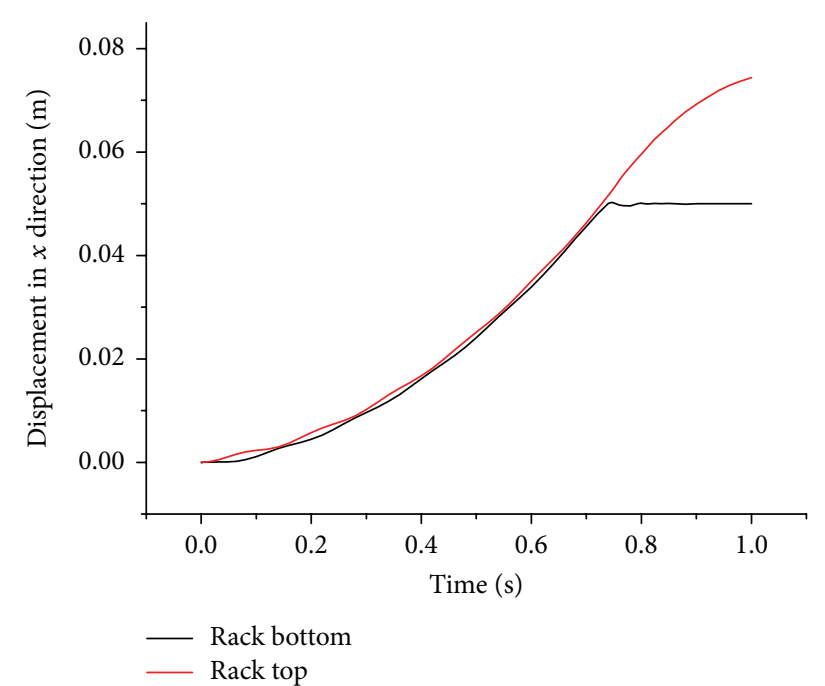

(a)

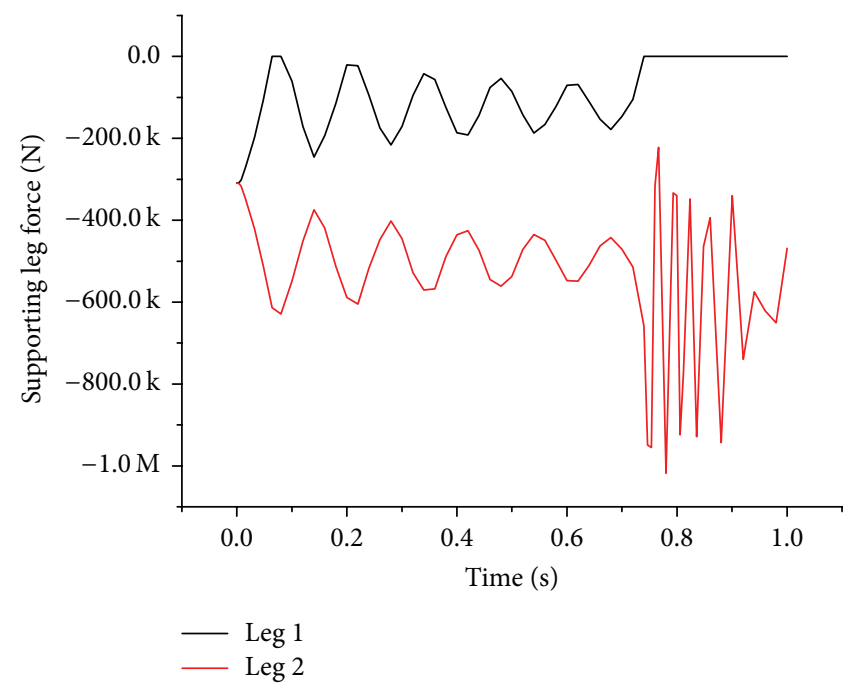

(b)

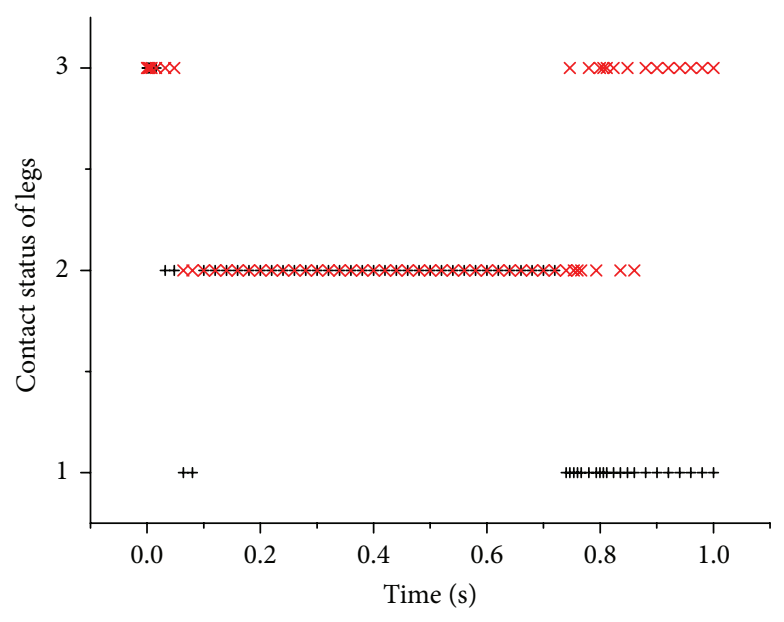

$+\operatorname{Leg} 1$

$\times \operatorname{Leg} 2$

(c)

FIGURE 7: Uniform acceleration amplitude loading: $0.10 \mathrm{~g}$.

TABLE 3: Description of loading cases.

\begin{tabular}{lcc}
\hline Loading number & Description & Acceleration amplitude \\
\hline 1 & $\begin{array}{c}\text { Uniform acceleration } \\
\text { amplitude }\end{array}$ & $0.06 \mathrm{~g}$ \\
2 & $\begin{array}{c}\text { Uniform acceleration } \\
\text { amplitude }\end{array}$ & $0.10 \mathrm{~g}$ \\
3 & $\begin{array}{c}\text { Uniform acceleration } \\
\text { amplitude }\end{array}$ & $0.16 \mathrm{~g}$ \\
4 & $\begin{array}{c}\text { Sine wave with } \\
\text { frequency of } 1 \mathrm{~Hz} \\
\text { Seismic loading }\end{array}$ & $0.40 \mathrm{~g}$ \\
\hline
\end{tabular}

parameter STAT representing the status of contact between legs and floor. If STAT $=3$, contact is closed and no sliding occurs. If STAT $=1$, contact is open. If STAT $=2$, relative sliding occurs.
Figure 6 shows when the rack is subjected a uniformed acceleration of $0.06 \mathrm{~g}$ in $X$ direction, the rack has a $0.8 \mathrm{~mm}$ displacement and then remain still in the bottom which means no sliding occurs. The displacement fluctuation at the top may be caused by vibration of the rack itself.

Figure 7 shows the rack motion subjected to $0.10 \mathrm{~g}$ acceleration larger than the critical sliding acceleration. In the previous 0.7 seconds, the displacement of rack tended to be classical quadric curve which means sliding occurs. As shown in (c), the contact status remains the sliding and no overturning emerged. The transient overturning in the previous 0.2 seconds may be caused by the transient phenomenon of the loading. At 0.7 seconds, the bottom leg impacts the wall.

Figure 8 shows the rack motion subjected to $0.16 \mathrm{~g}$ acceleration lager than the critical overturning acceleration. It is clear in Figure 8(a) that overturning, sliding, and impact 


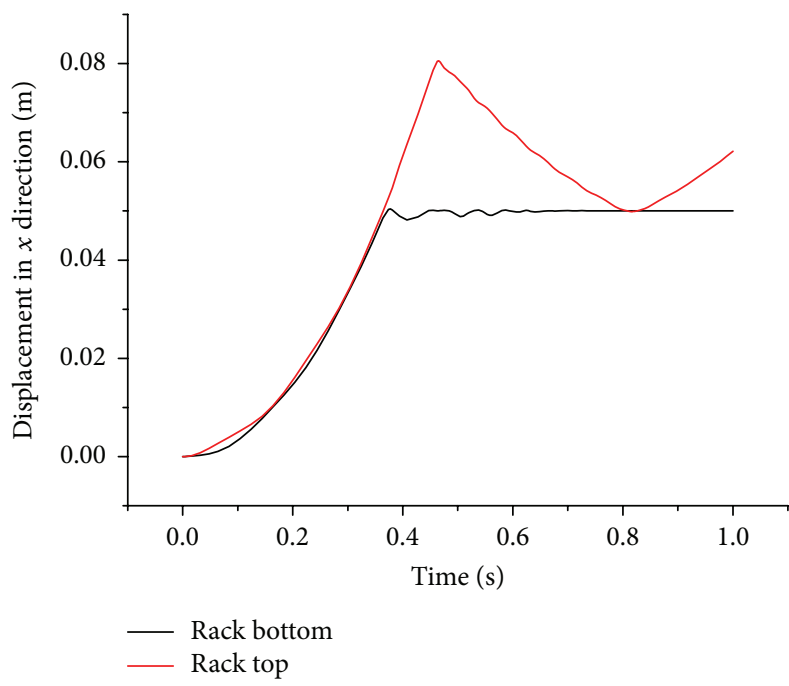

(a)

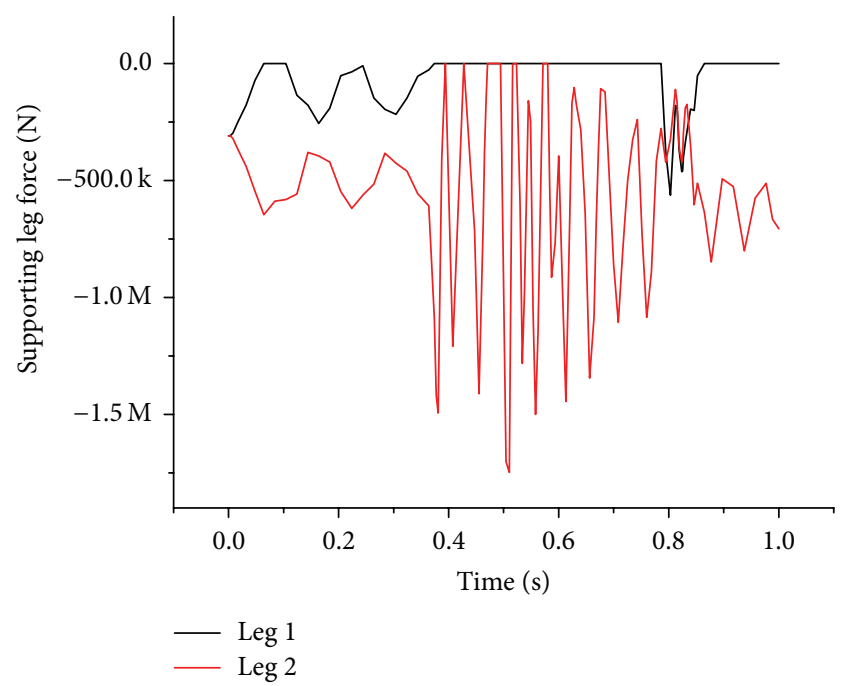

(b)

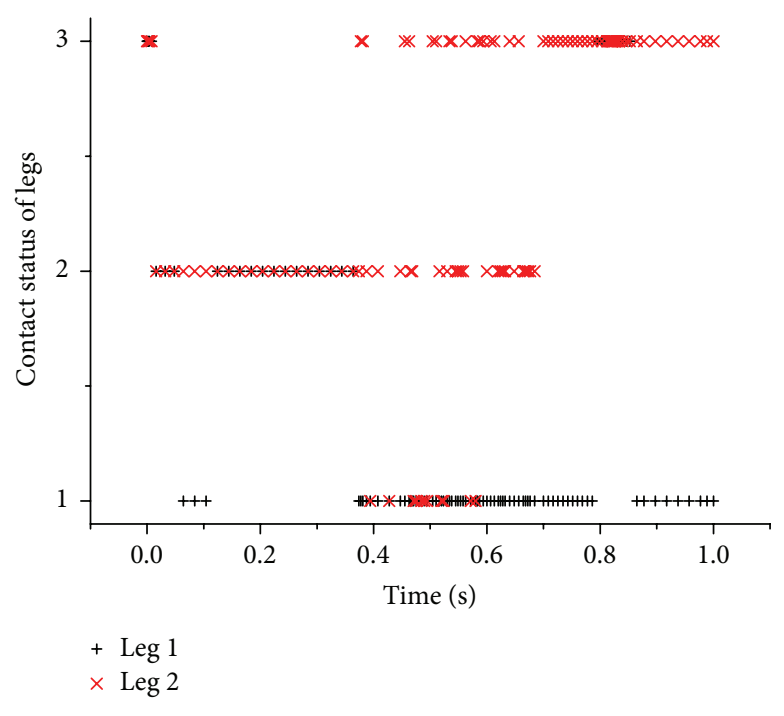

(c)

FIgURE 8: Uniform acceleration amplitude loading: $0.16 \mathrm{~g}$.

occur; the rack bottom impacts the wall because the bottom plate is $30 \mathrm{~mm}$ larger than rack top. As Figure 8(c) shows, from 0.4 to $1.0 \mathrm{~s}$, the contact of Leg 1 opens leading to the zero force in Figure 8(b) which verified rack overturns.

Figure 9 shows the rack motion subjected to a sine wave with acceleration amplitude of $0.4 \mathrm{~g}$. Both the bottom and the top of the rack impact the side wall because the acceleration amplitude surpasses both the critical sliding and overturning acceleration.

Figure 10 shows the rack motion subjected a seismic loading illustrated in Figure 11 with a peak ground acceleration of $0.4 \mathrm{~g}$. The rack top and bottom move almost simultaneously. At $2.8 \mathrm{~s}$, the rack impacts the wall.

Finally, these transient tests prove that the FEM model in Section 2 can be used to study the sliding and overturning of the rack.

\section{Discussion on Friction Coefficient and Gap Sizes}

In this section, different gap sizes and friction coefficients are discussed to investigate the rack response based on the FEM model in Section 2. The total 9 sets of parameter combinations are calculated in this section with gap sizes ranging from 20 to 60 and friction coefficients ranging from 0.2 to 0.8 . The seismic loading illustrated in Figure 11 with a peak ground acceleration of $0.4 \mathrm{~g}$ is applied in $X$ direction. The critical sliding acceleration, critical overturning acceleration, maximum bottom and top displacement responses, and the maximum bottom and top impacts are listed in Table 4.

In the previous section, the critical sliding acceleration is determined by $m /\left(m_{H}+m\right)$ times $\mu g$. This means the rack will slide relatively on the floor only when the ground 


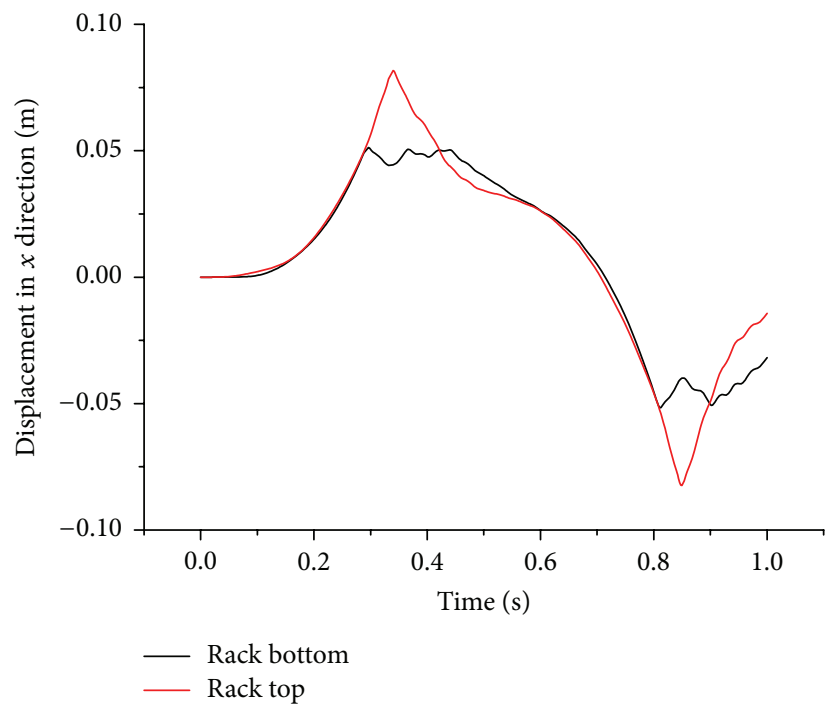

(a)

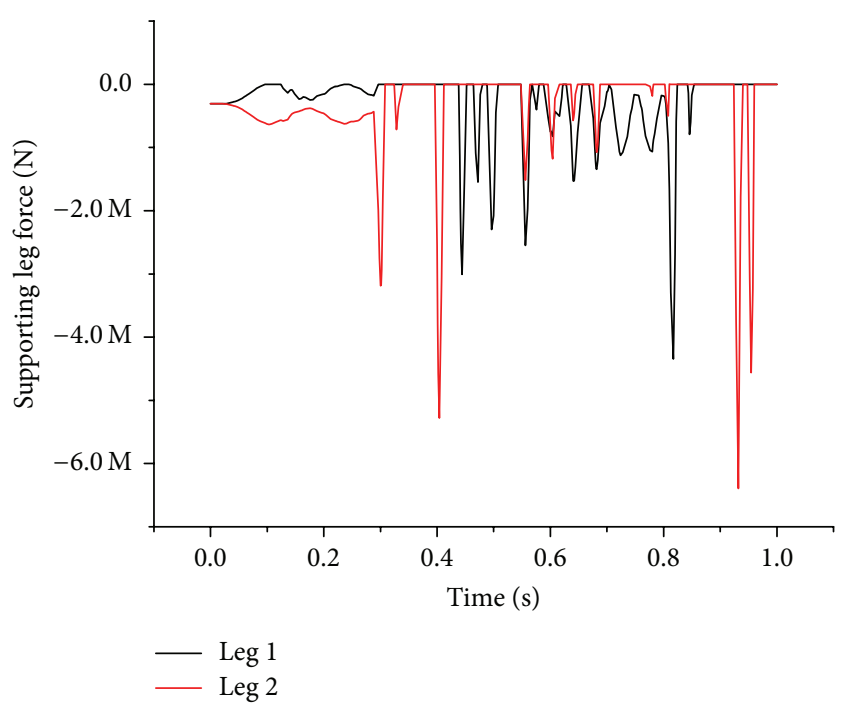

(b)

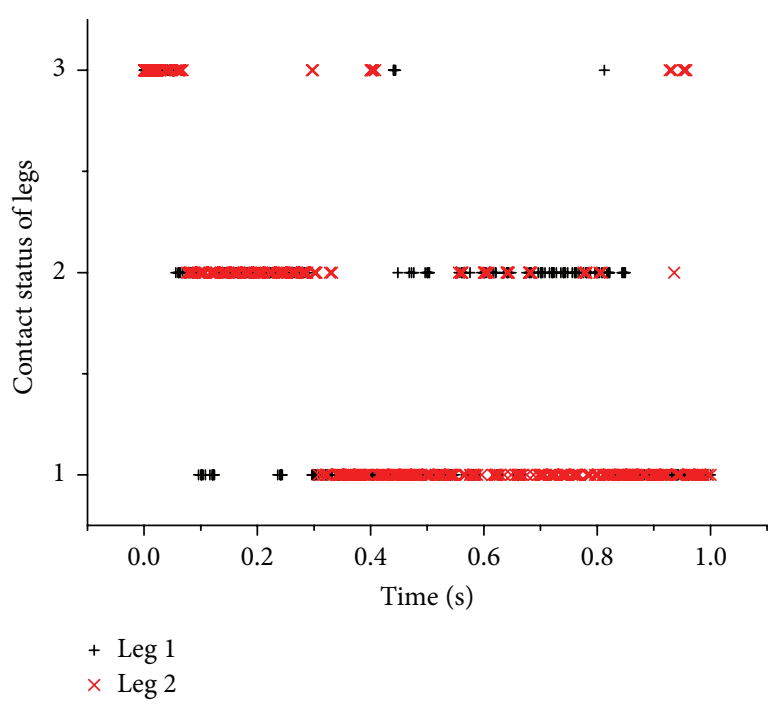

(c)

FIgURE 9: Sine acceleration amplitude loading: $0.4 \mathrm{~g}, 1 \mathrm{~Hz}$.

acceleration surpasses this threshold value. If the friction coefficient increases, the critical sliding acceleration will be larger; therefore, the rack is less likely to relatively slide on the floor and impact the wall. When the energy dissipation (friction force) increases there is a reduction of the elevation of fluid waves $[3,4]$. Similarly, there should be a reduction of the response displacement and impact force when the friction coefficient increases. As shown in Table 4, this phenomenon is basically true for all gap sizes, especially for Cases 4 to 6 .

However, there are some exceptions for this correlation. For example, the maximum bottom impact force for Case 2 is smaller than that for Case 3. These exceptions may be caused by the randomness of the seismic wave. Here is the possible reason. For Cases 1 to 3, the critical sliding accelerations are $0.028 \mathrm{~g}, 0.042 \mathrm{~g}$, and $0.11 \mathrm{~g}$, respectively. If the peaks of earthquake wave that surpass the critical accelerations are in the same direction, the rack will move closely to the wall and may impact the wall. On the contrary, if the peaks of earthquake wave that surpass the critical accelerations are in different directions, the rack may just remain still. For the same seismic wave, if the friction coefficient changes, the peaks that surpass the threshold change. Consequently, the impact forces calculated with smaller friction coefficient are possibly smaller than the larger ones in a single transient test.

As the statement in Section 3.1, if critical overturning acceleration is larger than critical sliding, the rack will not overturn. The results in Case 6 have proved this statement. In Case 6, the rack top impacts the wall although the bottom does not. For Case 6, the critical overturning acceleration is $0.118 \mathrm{~g}$, the critical sliding acceleration is $0.186 \mathrm{~g}$, and, therefore, the rack is much more likely to overturn than slide. Consequently, the rack bottom does not impact the wall and the rack top impacts the wall possibly because of overturning. 


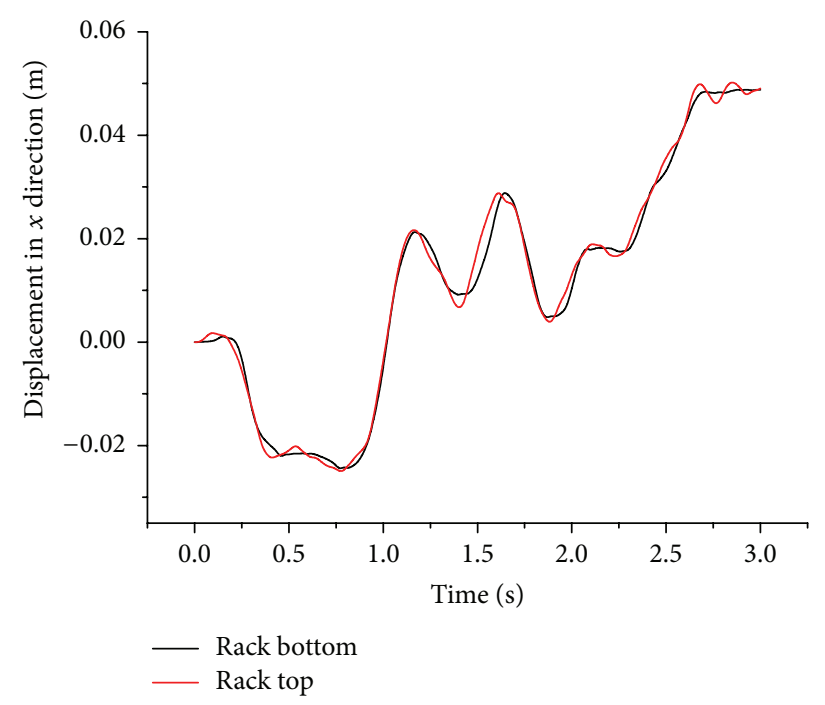

(a)

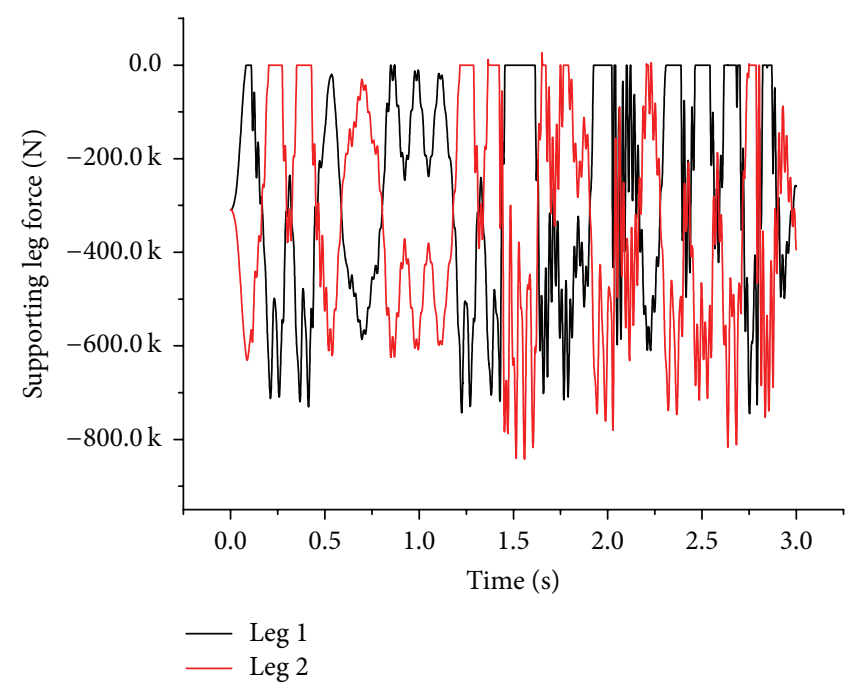

(b)

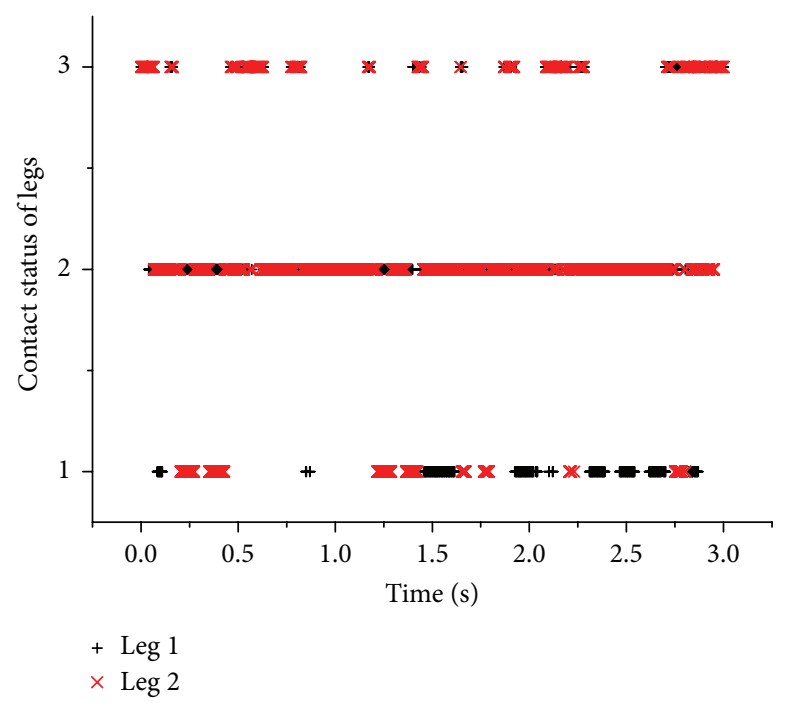

(c)

FIGURE 10: Test Loading 5: seismic loading with peak ground acceleration $0.40 \mathrm{~g}$.

TABLE 4: The maximum results of the 9 sets of parameters combinations.

\begin{tabular}{|c|c|c|c|c|c|c|c|c|}
\hline $\begin{array}{l}\text { Case } \\
\text { number }\end{array}$ & Gap sizes/mm & $\mu$ & $\begin{array}{c}\text { Critical } \\
\text { sliding acc./g }\end{array}$ & $\begin{array}{c}\text { Critical } \\
\text { overturning } \\
\text { acc./g }\end{array}$ & Bottom disp./mm & Top disp./mm & $\begin{array}{l}\text { Bottom } \\
\text { impact } \\
\text { force/N }\end{array}$ & Top impact force/ $\mathrm{N}$ \\
\hline 1 & 20 & 0.2 & 0.028 & 0.070 & 20.2 & 50.1 & $3.29 E 7$ & $3.24 E 7$ \\
\hline 2 & 20 & 0.3 & 0.042 & 0.070 & 20.2 & 50.1 & $1.21 E 7$ & $5.38 E 6$ \\
\hline 3 & 20 & 0.8 & 0.111 & 0.070 & 20.1 & 50.1 & $2.13 E 7$ & $2.89 E 7$ \\
\hline 4 & 40 & 0.2 & 0.047 & 0.118 & 40.1 & 63.9 & $5.10 E 6$ & - \\
\hline 5 & 40 & 0.3 & 0.070 & 0.118 & 40.2 & 43.85 & $2.461 E 6$ & - \\
\hline 6 & 40 & 0.8 & 0.186 & 0.118 & 35.5 & 70.1 & - & $2.70 E 6$ \\
\hline 7 & 60 & 0.2 & 0.060 & 0.152 & 60.1 & 69.9 & $4.92 E 6$ & - \\
\hline 8 & 60 & 0.3 & 0.090 & 0.152 & 50.2 & 52.57 & - & - \\
\hline 9 & 60 & 0.8 & 0.240 & 0.152 & 54.8 & 56.11 & - & - \\
\hline
\end{tabular}




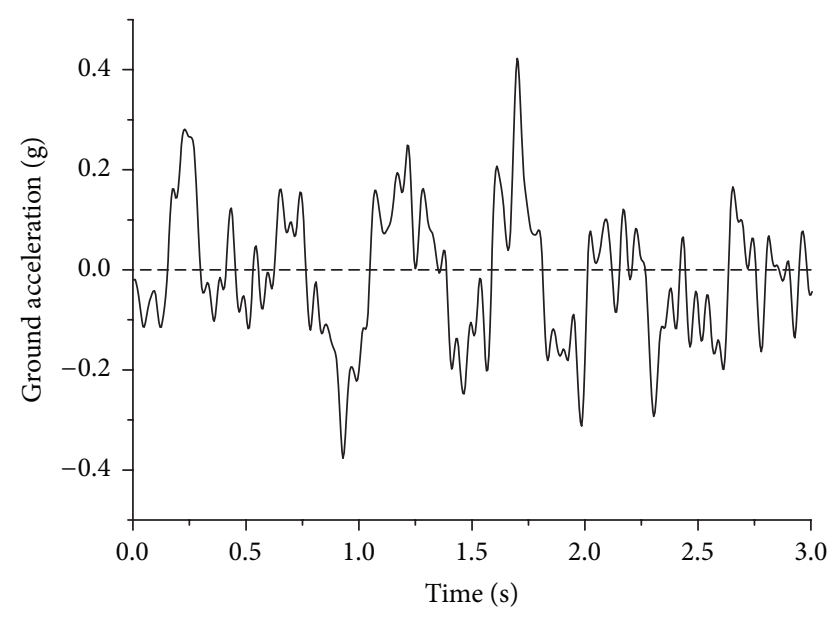

Figure 11: Seismic wave.

Another finding is that when the gap between rack and the pool wall is larger, the rack is less likely to impact the wall. For Cases 1, 4, and 7, with increasing gaps, the impact forces decrease. This phenomenon is obvious because larger gap means larger sliding distance; the friction force will dissipate more energy with larger sliding distance; therefore, it is less possible to impact with larger gap.

\section{Conclusions}

This paper concentrates on the seismic response of spent fuel rack including phenomena like sliding, overturning, and impact between rack and spent fuel pool wall. The AP1000 spent fuel rack is analyzed by an FEM model with ANSYS codes regarding effects including friction and impact. The FEM model regards the assemblies as a part of rack and ignores the impact between racks and assemblies. Based on D'Alambert's principle, the equilibriums of force and momentum were established to obtain the critical sliding and overturning acceleration. Then, 5 characteristic transient loadings designed according to the critical sliding and overturning acceleration were applied to the rack FEM model to test the sliding and overturning. A discussion on fluid gap sizes and supporting leg friction coefficient was carried out to estimate the most important factor influencing the rack displacement and impact forces.

The detailed conclusions are listed below:

(1) The fluid added mass can decrease the critical sliding and overturning acceleration.

(2) There is a positive correlation between friction coefficient and the critical sliding acceleration.

(3) When friction coefficient increases, the sliding distance and impact force tend to be smaller. However, there are some exceptions, possibly on account of the randomness of the seismic waves.

(4) If the critical sliding acceleration is larger than critical overturning acceleration, the rack is much more likely to overturn than slide.
(5) When the gap between the rack and the pool wall is larger, the rack is less likely to impact the wall.

This paper can guide the design of the future's fluidstructure interaction experiment for spent fuel rack. With the proper set of parameters including loading amplitudes and gap sizes, the nonlinear phenomena including the friction effect, the impact effect, and the FSI effect can be evaluated independently with higher accuracy.

\section{Competing Interests}

The authors declare that they have no competing interests.

\section{Acknowledgments}

The project was sponsored by National Science and Technology Major Project of the Ministry of Science and Technology of China (2015ZX06004002-003).

\section{References}

[1] Y. Zhao, P. R. Wilson, and J. D. Stevenson, "Nonlinear 3-D dynamic time history analysis in the reracking modifications for a nuclear power plant," Nuclear Engineering and Design, vol. 165, no. 1-2, pp. 199-211, 1996.

[2] R. Lo Frano, "Evaluation of the fluid-structure interaction effects in a lead-cooled fast reactor," Nuclear Technology, vol. 189, no. 1, pp. 1-10, 2015.

[3] R. Lo Frano and G. Forasassi, "Conceptual evaluation of fluidstructure interaction effects coupled to a seismic event in an innovative liquid metal nuclear reactor," Nuclear Engineering and Design, vol. 239, no. 11, pp. 2333-2342, 2009.

[4] F. Axisa and J. Antunes, Modelling of Mechanical Systems: FluidStructure Interaction, Butterworth-Heinemann, Boston, Mass, USA, 2007.

[5] H. Ashar and G. DeGrassi, "Design and analysis of freestanding spent fuel racks in nuclear power plants: an overview," in Proceedings of the 10th International Conference on Structural Mechanics in Reactor Technology (SMIRT '89), Brookhaven National Laboratory, Anaheim, Calif, USA, August 1989, http://www.osti.gov/scitech/biblio/6126846-TH01gM/.

[6] M. Hinderks, H. Ungoreit, and G. Kremer, "Improved method to demonstrate the structural integrity of high density fuel storage racks," Nuclear Engineering and Design, vol. 206, no. 2-3, pp. 177-184, 2001.

[7] C. Li, H. Qian, K. Zhang, Y. Xie, and D. Xu, "Time history analysis method for spent fuel racks," Nuclear Techniques, vol. 36, no. 4, p. 7, 2013.

[8] G. M. Lee, K. S. Kim, K. B. Park, and J. K. Park, "Threedimensional seismic analysis for spent fuel storage rack," Journal of the Korean Nuclear Society, vol. 30, pp. 91-98, 1998.

[9] A. Iwasaki, Y. Nekomoto, H. Morita et al., "Analysis study on free standing rack under the earthquake excitation," in Proceedings of the ASME Pressure Vessels and Piping Conference (PVP '12), pp. 261-267, Toronto, Canada, July 2012.

[10] Westinghouse, "Spent fuel storage rack structure/seismic analysis," Tech. Rep. 54, 2009.

[11] J. Stabel and M. Ren, "Fluid-structure-interaction for the analysis of the dynamics of fuel storage racks in the case of 
seismic loads," Nuclear Engineering and Design, vol. 206, no. 2-3, pp. 167-176, 2001.

[12] A. Iwasaki, Y. Nekomoto, H. Morita et al., "Experimental parameter study on free standing rack," in Proceedings of the ASME Pressure Vessels and Piping Conference, Paper No. PVP2012-78458, pp. 171-179, Toronto, Canada, July 2012. 

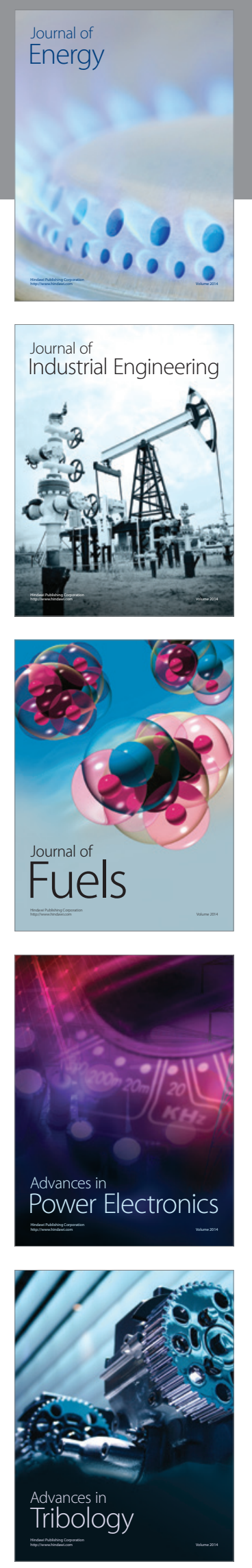
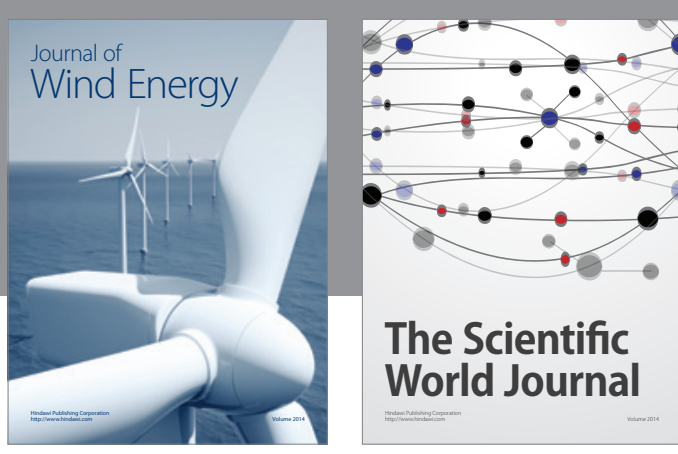

The Scientific World Journal
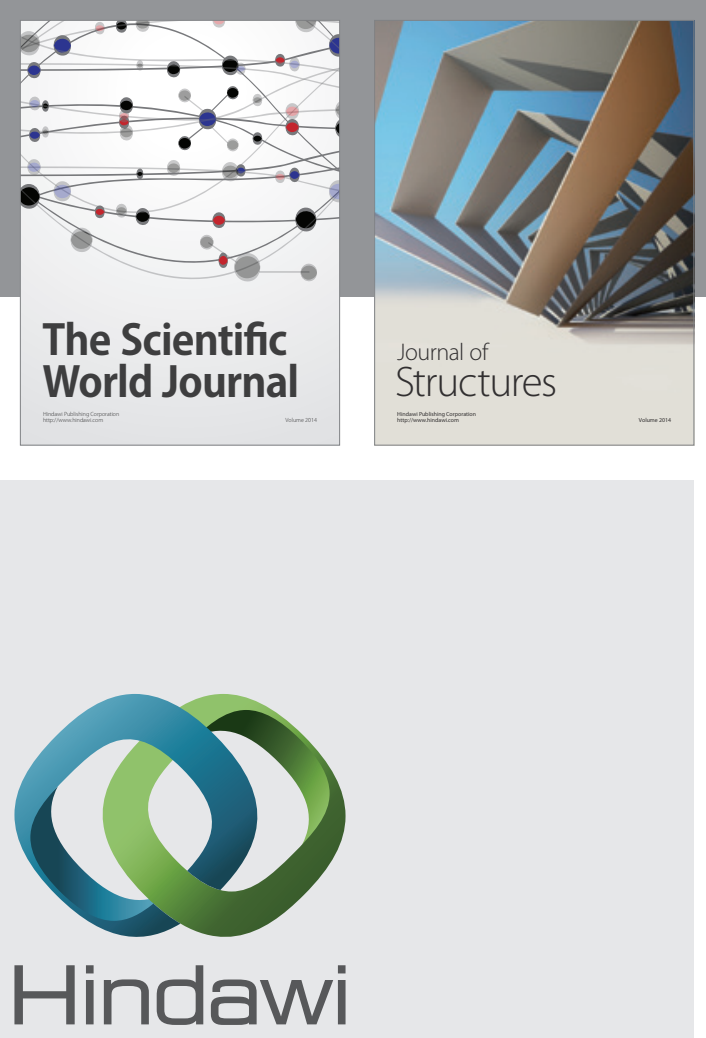

Submit your manuscripts at

http://www.hindawi.com
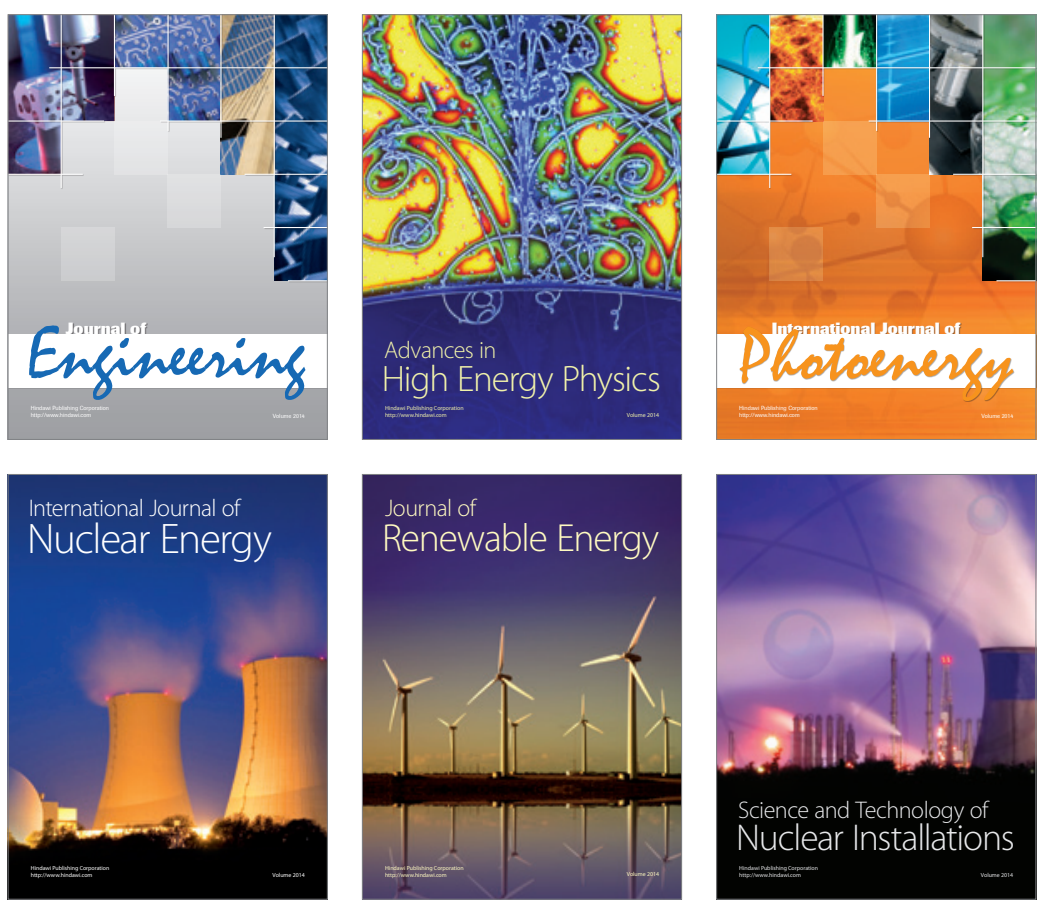
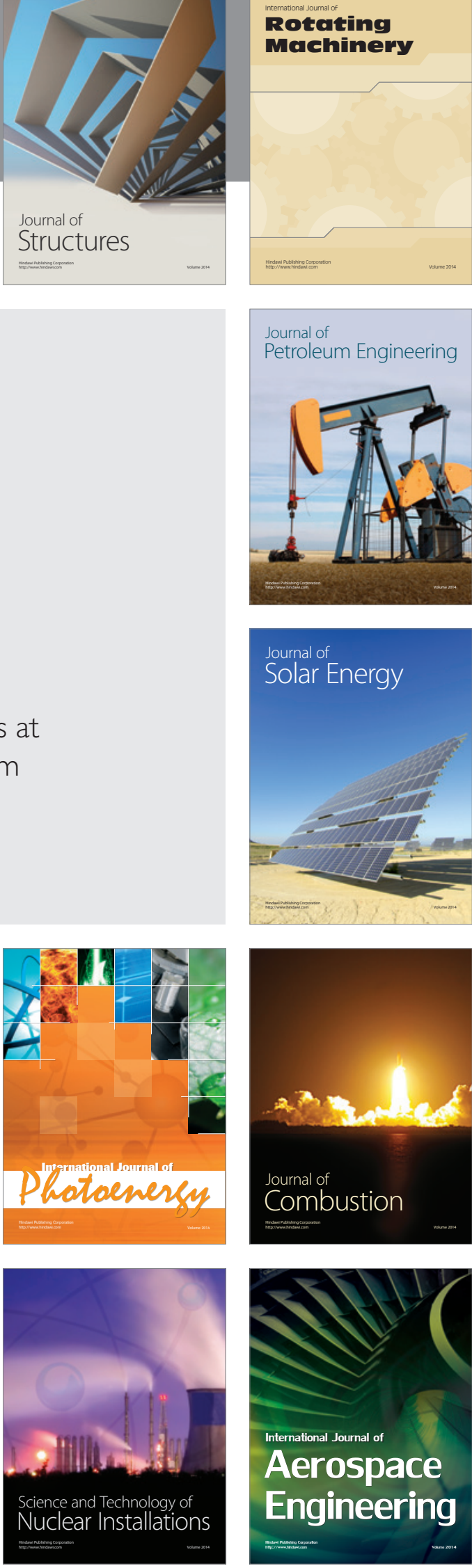